\title{
Paleobiogeographic evolution and distribution of Carcharodontosauridae (Dinosauria, Theropoda) during the middle Cretaceous of North Africa
}

\author{
Carlos Roberto dos Anjos Candeiro, ${ }^{1,4}$; Stephen Louis Brusatte ${ }^{2}$; Luciano Vidal ${ }^{1,5}$ \& Paulo Victor Luiz Gomes da Costa Pereira ${ }^{3}$
}

1 Universidade Federal de Goiás (UFG), Laboratório de Paleontologia e Evolução (LABPALEOEVO), Curso de Geologia. Aparecida de Goiânia, G0, Brasil.

${ }^{2}$ University of Edinburgh, Grant Institute, School of GeoSciences. Edinburgh, Scotland, UK. ORCID: 0000-0001-7525-7319.

E-mail: s.brusate@gmail.com

${ }^{3}$ Universidade Federal do Rio de Janeiro (UFRJ), Instituto de Geociências (IGE0), Departamento de Geologia, Laboratório de Macrofósseis. Rio de Janeiro, RJ, Brasil. ORCID: 0000-0001-5946-3251. E-mail: paulovictor.29@yaho0.com.br

${ }^{4}$ ORCID: 0000-0002-8128-4660. E-mail: candeiro@ufg.br

${ }^{5}$ ORCID: 0000-0001-9034-6985. E-mail: sciencevidal@gmail.com

\begin{abstract}
Over the last few decades, the systematics and evolution of carcharodontosaurids, a group of large predatory dinosaurs, from North Africa have been better understood mainly due the discovery of new species. We review this record here and discuss its importance for understanding the evolution and ecology of these dinosaurs. North Africa has one of the best records of carcharodontosaurid species. These species show dietary specializations and paleogeographic distributions similar to other top predatory theropods such as Abelisauridae and Spinosauridae. However, carcharodontosaurids have a wider distribution than other large theropods. The middle Cretaceous of North Africa was characterized by the niche overlap between large predators. This evidence increases our understanding of the evolution of Carcharodontosauridae in a highly competitive region, a conjuncture rarely reported for large top predators.
\end{abstract}

Key-Words. Carcharodontosauridae; Gondwana; Middle Cretaceous; North Africa; Overlap.

\section{INTRODUCTION}

Several species of predatory dinosaurs are grouped in the family Carcharodontosauridae, a subgroup of basal tetanuran allosauroid theropods closely related to the well-known Allosaurus (Brusatte \& Sereno, 2008; Benson et al., 2010; Carrano et al., 2012). Some of these species are among the largest theropods to ever live, with Carcharodontosaurus, Giganotosaurus, and Acrocanthosaurus approaching the famous Tyrannosaurus rex in size (ca. 12 meters in total body length, 3+ tons in mass: Benson et al., 2014). Carcharodontosauridae had its main evolutionary radiation during the Early Cretaceous in Gondwana, but also has been recorded in some areas of Laurasia (e.g., Acrocanthosaurus, Concavenator, Shaochilong, Kelmayisaurus). This cosmopolitan distribution differs from the more limited distribution of some other large theropods, particularly tyrannosaurids, which were restricted to the North America and Asia (e.g., Holtz, 2004; Brusatte et al., 2010a). During the early to middle part of the Cretaceous, carcharodontosaurids were among the most important large-bodied predatory dinosaurs globally, and were apex predators in many terrestrial ecosystems.
During the Early Cretaceous (late AptianCenomanian), carcharodontosaurids were diverse and widespread in South American and Africa, particularly the northern parts of Africa that are now covered by the Sahara Desert. These Gondwanan carcharodontosaurids occupied the same areas as two other groups of large theropods, the sail-backed spinosauroids and the shortfaced and small-armed abelisauroids. Indeed, fossils of these three groups are often found together (e.g., Medeiros \& Schultz, 2002; Brusatte \& Sereno, 2007; Sereno \& Brusatte, 2008). The diversity of carcharodontosaurids begins to decrease sometime during or after the Cenomanian, and no unequivocal fossils of the group have yet been found in the post-Cenomanian deposits of Gondwana. It appears, therefore, as if carcharodontosaurids went extinct in Gondwana by the Turonian, replaced by other large predatory dinosaurs such as megaraptorids and abelisaurids (Novas et al., 2013). They apparently persisted longer in Laurasia, as the Chinese Shaochilong dates to the Turonian (Brusatte et al., 2009), but sometime during the early-middle Late Cretaceous they were replaced as apex predators in North America and Asia by tyrannosauroids (Brusatte et al., 2009, 2010a; Zanno \& Makovicky, 2013). 
Some of the best records of large carcharodontosaurids come from the Lower Cretaceous rocks of Egypt, Niger, Morocco and Tunisia, in North Africa. This region underwent a complex paleogeographic history during the time that carcharodontosaurids thrived, as it was completely severed from Europe by the middle Cretaceous and was fragmented by high sea levels.

In this review we discuss the evolution and paleobiogeography of carcharodontosaurids from the middle Cretaceous of North Africa, with the aim of understanding the distribution and ecological role of these large theropods. We focus on the fossil record of the formally described species. As considerable new material of carcharodontosaurids has been discovered in North Africa in recent years, this review is an attempt to summarize our understanding of this group as it currently stands.

\section{Characteristics}

Carcharodontosaurids are a subgroup of Allosauroidea, "a major clade of basal tetanuran theropods that also includes Allosauridae (Allosaurus and kin), Metriacanthosauridae (= Sinraptoridae, including Sinraptor and close relatives), and Neovenatoridae (Neovenator and most likely the megaraptorans)" (Benson et al., 2010; Carrano et al. 2012 and references therein) (Fig. 1). Allosauroids are mid-to-large size theropods diagnosed by several characters, including a large promaxillary fenestra in the maxilla, pneumatic nasals, lateral crests on the nasals, a large knob on the supraoccipital, and L-shaped chevrons in the middle part of the tail (Carrano et al., 2012).

Carcharodontosauridae is phylogenetically defined as the most inclusive clade containing Carcharodontosaurus saharicus Depéret \& Savornin, 1927 but not Allosaurus fragilis Marsh, 1877, Sinraptor dongi Currie \& Zhao, 1993, Passer domesticus (Linnaeus, 1758) (definition from Sereno et al., 2005, see also Brusatte \& Sereno, 2008).
According to the large-scale basal theropod phylogenetic analysis of Carrano et al. (2012), carcharodontosaurids are diagnosed by several characters, including a short or absent anterior ramus of the maxilla, hyposphenes in the dorsal vertebrae that are comprised of parallel sheets, tall neural spines in the dorsal vertebrae, and a peg-andsocket articulation between the ilium and ischium.

The name-bearing taxon for Carcharodontosauridae is the genus Carcharodontosaurus, which means "a lizard with shark tooth - Carcharodon". This genus was named by Stromer (1931) based on a disarticulated skeleton found in the Cenomanian of Egypt. In naming this dinosaur, Stromer was inspired by similarities between its dentition and teeth of the great Cenozoic shark Carcharodon. Carcharodontosaurid teeth are relatively wide, laterally compressed, finely serrated, and have wrinkles on the enamel surface (e.g., Sereno et al., 1996; Brusatte et al., 2007; Hendrickx \& Mateus, 2014).

In general, the North African carcharodontosaurids were mid-to-large theropods, with estimated total body lengths ranging from an estimate 6-8 meters in Eocarcharia (Sereno \& Brusatte, 2008) to 12 meters in Carcharodontosaurus (Sereno et al., 1996) and perhaps Sauroniops (Cau et al., 2012). They and other carcharodontosaurids had many distinctive features of the anatomy, including sculptured facial bones (particularly the maxilla), thickened and fused bones of the skull roof, extensively fused braincases, and a heavily pneumatized postcranial skeleton (e.g., Stromer, 1931; Stovall \& Langston, 1950; Coria \& Salgado, 1995; Sereno et al., 1996; Coria \& Currie, 2002, 2006; Novas et al., 2005; Brusatte \& Sereno, 2007, 2008; Sereno \& Brusatte, 2008; Brusatte et al., 2009, 2010b; Ortega et al., 2010; Eddy \& Clarke, 2011; Cau et al., 2012) . Where known, the forelimbs of carcharodontosaurids are larger and more robust than those of some other large theropods (tyrannosaurids and abelisaurids), and they had three fingers in the hand. The hindlimbs are robust and stocky, seemingly well adapted for bearing the heavy weight of these animals.

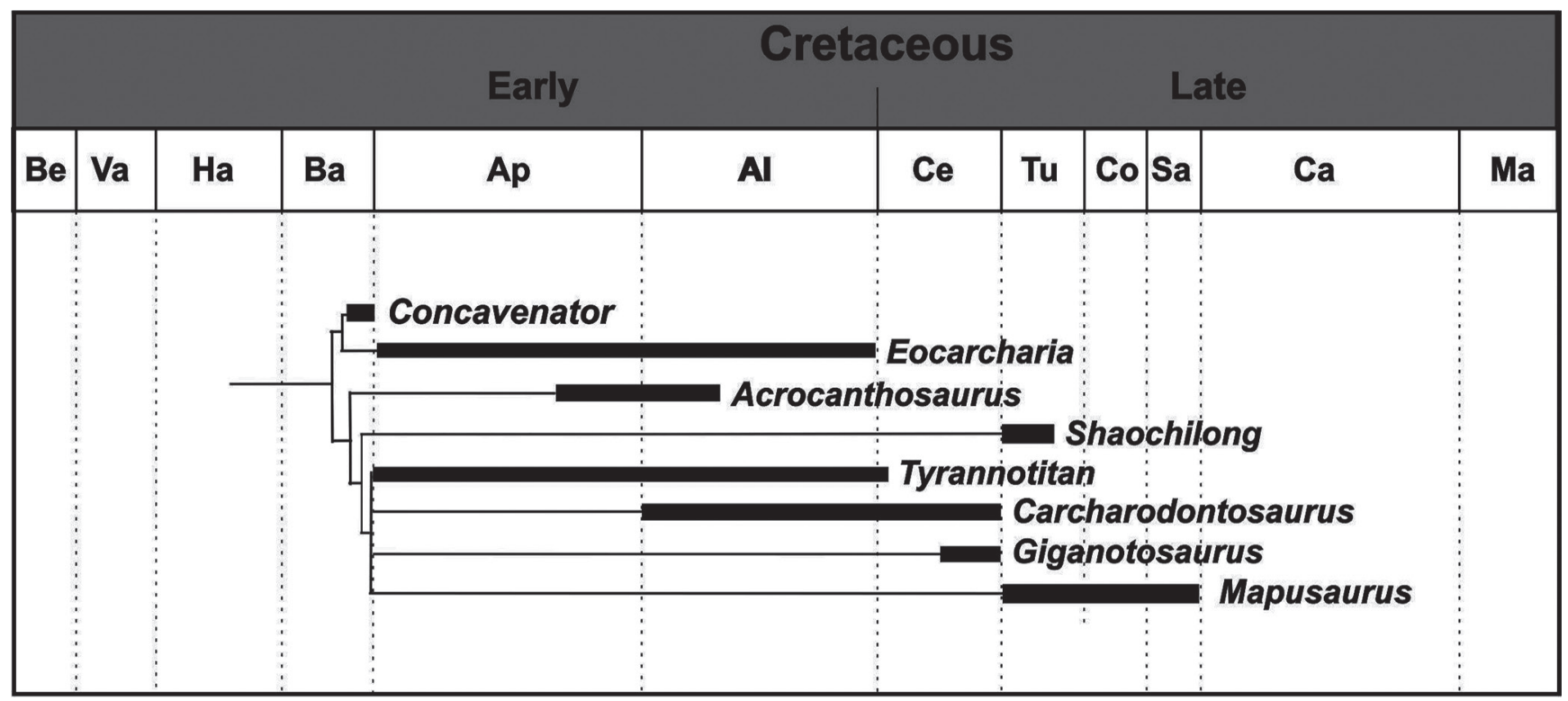

Figure 1. Phylogenetic relationships and geochronological distribution of the best-known species of Carcharodontosauridae (according to Carrano et al., 2012). 


\section{Diet composition and environmental habitat}

Carcharodontosaurids possessed generally tall and short skulls, a feature shared with most large theropods, but differing from the more elongate skulls of tyrannosauroids and the shorter and deeper skulls of abelisaurids. All of these theropods, however, had a carnivorous diet that included dinosaurs and other vertebrates (e.g., Lü et al., 2014). Along with the North African spinosaurids, carcharodontosaurids and abelisaurids are recorded in portions of the continent with marine influence and records of a diverse terrestrial and aquatic fauna.

Spinosauridae is a group of large-to-supersized theropod dinosaurs found in Africa, Asia, Europe, and South America (Stromer, 1915; Buffetaut \& Ingavat, 1986; Charig \& Milner, 1986; Sereno et al., 1998; Ibrahim et al., 2014). These dinosaurs have an elongated skull, subconical teeth, and dorsally displaced nostrils (Sereno et al., 1998). This morphology gives unique characteristics to this group, similar in many ways to modern crocodylians such as gavials (e.g., Cuff \& Rayfield, 2013). Many studies show that the Spinosauridae had a piscivorous diet (Charig \& Milner, 1986; Kitchener, 1987; Sereno et al., 1998; Rayfield et al., 2007; Milner, 2003; Amiot et al., 2010; Ibrahim et al., 2014). Nevertheless, evidence suggest that the spinosaurids were not exclusively piscivorous, but also fed on other tetrapods (Charig \& Milner, 1997; Gatesy \& Amato, 2008; Buffetaut et al., 2004; Kellner, 2004).

\section{Carcharodontosauridae species from the Cretaceous of North Africa}

Species: Carcharodontosaurus saharicus Stromer, 1931.

Body size: Estimated between 12 and 13 meters long.

Distribution and geological unit: Algeria - Continental intercalaire; Egypt - Bahariya Formation, Mut Formation; Morocco - Aoufous Formation, Kem Kem Formation; Niger - Continental intercalaire Formation, Echkar Formation, Elrhaz Formation; Tunisia -Chenini Formation, Continental intercalaire Formation (see Carrano et al., 2012 and Candeiro, 2015 all references herein).

\section{Geochronology: Albian-Cenomanian.}

General characteristics: Carcharodontosaurus was a colossal theropod dinosaur, estimated at over 12 meters in length and around 3 tons in body mass (Benson et al., 2014). It had a huge skull that was over 1.5 meters long, and clearly was an apex predator. Many studies (Dal Sasso et al., 2009; Eddy \& Clarke, 2011) have argued that C. saharicus was possibly larger than the great Tyrannosaurus rex, but smaller than Spinosaurus aegyptiacus, which is found in the same layers as Carcharodontosaurus. The first material of Carcharodontosaurus saharicus was two teeth from Algeria described by Depéret \& Savornin (1927). Better material was discovered in Egypt and described by Stromer (1931), but was unfortunately destroyed during an allied bombing raid in Munich during World
War II (Nothdurft et al., 2002). This dinosaur remained poorly known until the discovery of a nearly complete new skull in Morocco, described by Sereno et al. (1996).

Species: Carcharodontosaurus iguidensis Sereno \& Brusatte, 2007.

Body size: Estimated at between 12 and 13 meters long, based on the similar size of corresponding bones (e.g., maxilla) between it and the better known and closely related Carcharodontosaurus saharicus.

Distribution and geological unit: Niger, Echakar Formation.

\section{Geochronology: Cenomanian.}

General characteristics: This second species of Carcharodontosaurus was discovered on an expedition to Niger, led by Paul Sereno of the University of Chicago. It is known from several parts of the skull, including a maxilla, part of a lacrimal, a well-preserved braincase and posterior skull roof, and several teeth. These bones are generally similar in size and shape to those of Carcharodontosaurus saharicus, but lack numerous autapomorphies of C. saharicus and possess their own unique characters. As a result, Brusatte \& Sereno (2007) named this taxon as a new species of Carcharodontosaurus. They suggested that the presence of different species of this colossal theropod genus at generally the same time in Niger and Morocco may have been related to faunal differentiation, caused by shallow continental seas acting as barriers and isolating different parts of North Africa from each other.

Species: Eocarcharia dinops Sereno \& Brusatte, 2008.

Body size: Approximately between 6 and 8 meters long.

Distribution and geological unit: Niger, Elrhaz Formation.

\section{Geochronology: Aptian-Albian.}

General characteristics: Eocarcharia is a more basal carcharodontosaurid than Carcharodontosaurus, and is also several million years older. Like other carcharodontosaurids, it had a large bony 'brow' on the postorbital bone, above the orbit. This brow was heavily textured by vascular grooves and probably was covered by keratin in life (Sereno \& Brusatte, 2008).

Species: Sauroniops pachytholus Cau, Dalla-Vecchia \& Fabbri, 2012.

Body size: Unknown. Estimated by Cau et al. (2012) as 10-12 meters long, approximately the same size as Carcharodontosaurus.

Distribution and geological unit: Morocco, Kem Kem beds (Ifezouane Formation). 


\section{Geochronology: Cenomanian.}

General characteristics: The carcharodontosaurid Sauroniops pachytholus is known only from a single frontal, which was sold by a commercial dealer to a museum in Italy, but was argued to have most probably come from the Kem Kem beds. This bone differs from the frontals of other carcharodontosaurids in having a prominent bony dome on the dorsal surface of the frontal. This feature inspired this taxon's generic name: Sauron (Eye of Sauron) is a reference to the expressive eye on the top of a tower which represents Sauron, considered the main villain of the Lord of the Rings trilogy (see Cau et al., 2012). If the provenance information for this specimen is correct, it is found in the same layers as other large theropod dinosaurs - such as Deltadromeus and Spinosaurus. The phylogenetic relationships of this taxon are difficult to pin down because of the highly fragmentary material, but the cladistic analysis of Cau et al. (2012) found Sauroniops to group with Eocarcharia in a clade of basal carcharodontosaurids.

\section{DISCUSSION}

\section{Temporal and geographic distribution}

Over the last two decades, the discovery of many new fossils has revolutionized our understanding of carcharodontosaurid anatomy, distribution, phylogeny, and evolution, clarifying what was formerly a very poorly known group of large carnivorous dinosaurs. Many of these discoveries come from northern Africa, showing that this region was an important center of carcharodontosaurid evolution during the middle part of the Cretaceous.

The first diagnostic fossils of carcharodontosaurids come from the Late Jurassic of Africa (Veterupristisaurus milneri Rauhut, 2011 and other specimens reviewed therein), and over the next several tens of millions of years this group diversified and spread around the world. They achieved a cosmopolitan distribution, with many species recorded in Gondwana (particularly North Africa and South America), but also in Europe (Concavenator), Asia (Kelmayisaurus, Shaochilong), and North America (Acrocanthosaurus). Currently, there are more species of carcharodontosaurids known from North Africa (four) than any other part of the world.

In North Africa, the Carcharodontosauridae shared habitats with the large abelisaurids (Rugops, Kryptops) and spinosaurids (Suchomimus, Spinosaurus), forming a common triumvirate of large theropods (e.g., Brusatte \& Sereno, 2007; Sereno \& Brusatte, 2008) (Fig. 2). This triumvirate apparently persisted for a long period of time, as it is known from various formations of multiple ages (e.g., Aptian-Albian Elrhaz Formation, Cenomanian Echkar Formation, Cenomanian 'Kem Kem beds'). Thus, these predators could have competed due niche overlap, or their coexistence could be explained by niche partitioning. In fact, there are many records of dinosaur species found in the same layers that yield the large theropods of North Africa. These regions seem to have been particularly diverse, which may be explained by the paleogeography of the area. During the Aptian-Cenomanian many episodes of sea regression occurred, resulting in the formation of land connections between Africa-South America-Asia. These land connections may have allowed the terrestrial migration of Carcharodontosauridae (Sereno et al., 1996) and of other cosmopolitan tetrapods of the middle Cretaceous (e.g., Krause et al., 1997; Rauhut, 1999; Sues et al., 2002; Naish et al., 2004; Machado \& Kellner, 2005; Cavin et al., 2010; Lindoso et al., 2012; McFeeters et al., 2013; Fanti, 2009, 2012; Candeiro et al., 2011, Candeiro, 2015).

The presence of Carcharodontosauridae in the middle Cretaceous of North Africa shows that it is necessary to make a detailed biogeographic analysis of this period. However, the close relationship between Carcharodontosaurus saharicus, C. iguidensis, Eocarcharia dinops, and Sauroniops pachytholus with the South American carcharodontosaurids Giganotosaurus carolinii and Mapusaurus chubutensis, as well as the presence of carcharodontosaurids in North America, Europe, and Asia, reinforce the hypothesis of faunal interchange between the northern and southern continents during the middle Cretaceous (e.g., Brusatte, et al., 2009, 2010b and references therein; Candeiro, 2015). Indeed, there is growing evidence that many (but not all) dinosaur groups had a wide distribution during the Early to middle part of the Cretaceous, before faunas became more differentiated (provincial) in the Late Cretaceous, when the continents were widely separated (e.g., Brusatte et al., 2009, 2010b and references therein). However, the two other clades of large-bodied predators, Abelisauroidea and Spinosauridae, do not have such a widespread distribution as Carcharodontosauridae during the Earlymiddle Cretaceous, at least based on the currently known fossil record.

There are many possibilities to explain the pattern observed for the wide distribution of Carcharodontosauridae, which was marked during the middle Cretaceous. Although the rupture of Pangea occurred before this period, the faunal interchange of tetrapods during the Early-middle Cretaceous was made through several dispersal corridors. For example, the trans-Turgai connection was a corridor where faunal interchange between the northern and southern continents possibly occurred. During the middle Cretaceous, Europe was connected to Asia, and closely located to Northern Gondwana (Smith et al., 1994).

\section{Niche overlap}

In a biogeographical context, the Carcharodontosauridae from the middle Cretaceous of Africa are very interesting, as this region had a complex geological history during the fragmentation of Gondwana (Chen et al., 1993; Metcalfe, 2006). There is also growing evidence that parts northern South America (e.g., Araripe, Parnaíba, and São Luis basins) were inhabited by many of the same groups of dinosaurs as northern Africa during 
this time, including herbivorous species (rebbachisaurids, diplodocids, titanosaurids) and theropods (abelisaurids, neovenatorids, spinosaurids) (Candeiro, 2015). Future discoveries will help to test just how strong this biogeographic linkage was between the two regions during this time, and whether they were more closely linked to each other (in terms of shared faunas) than to other parts of the globe.
Carcharodontosaurids, abelisaurids, and spinosaurids seem to have had very similar diets, which included other tetrapods, and also fish for spinosaurids (Fig. 3). The consumption of tetrapods (especially other dinosaurs) was surely important to these often giant terrestrial predators. The major question is: how did these multiple groups of large predators co-exist with each other? There are several possibilities, which are difficult to test,

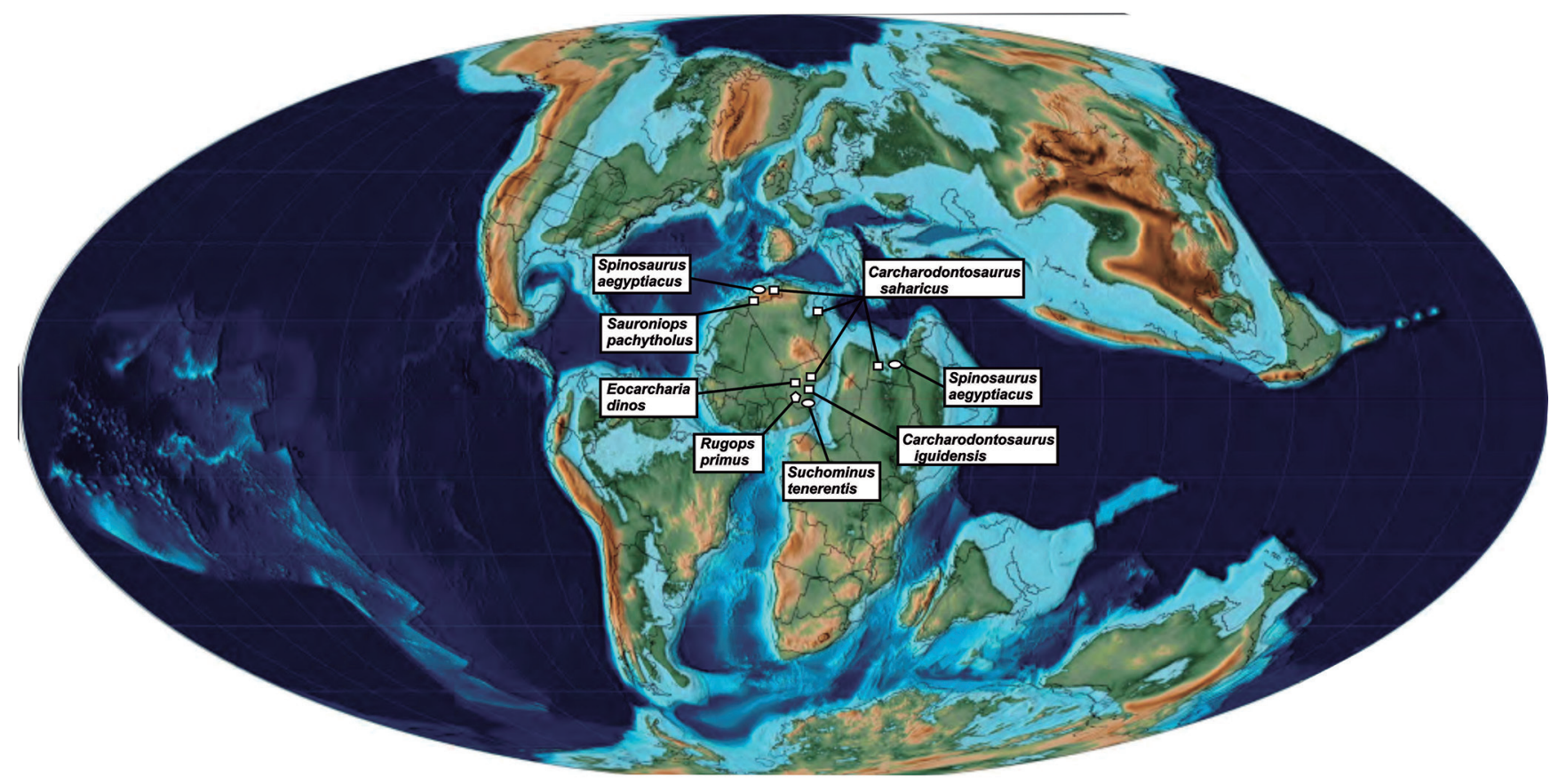

Figure 2. North African geographical distribution of the carcharodontosaurids, abelisaurids and spinosaurids during middle Cretaceous. Maps copyright CR Scotese Paleomap.

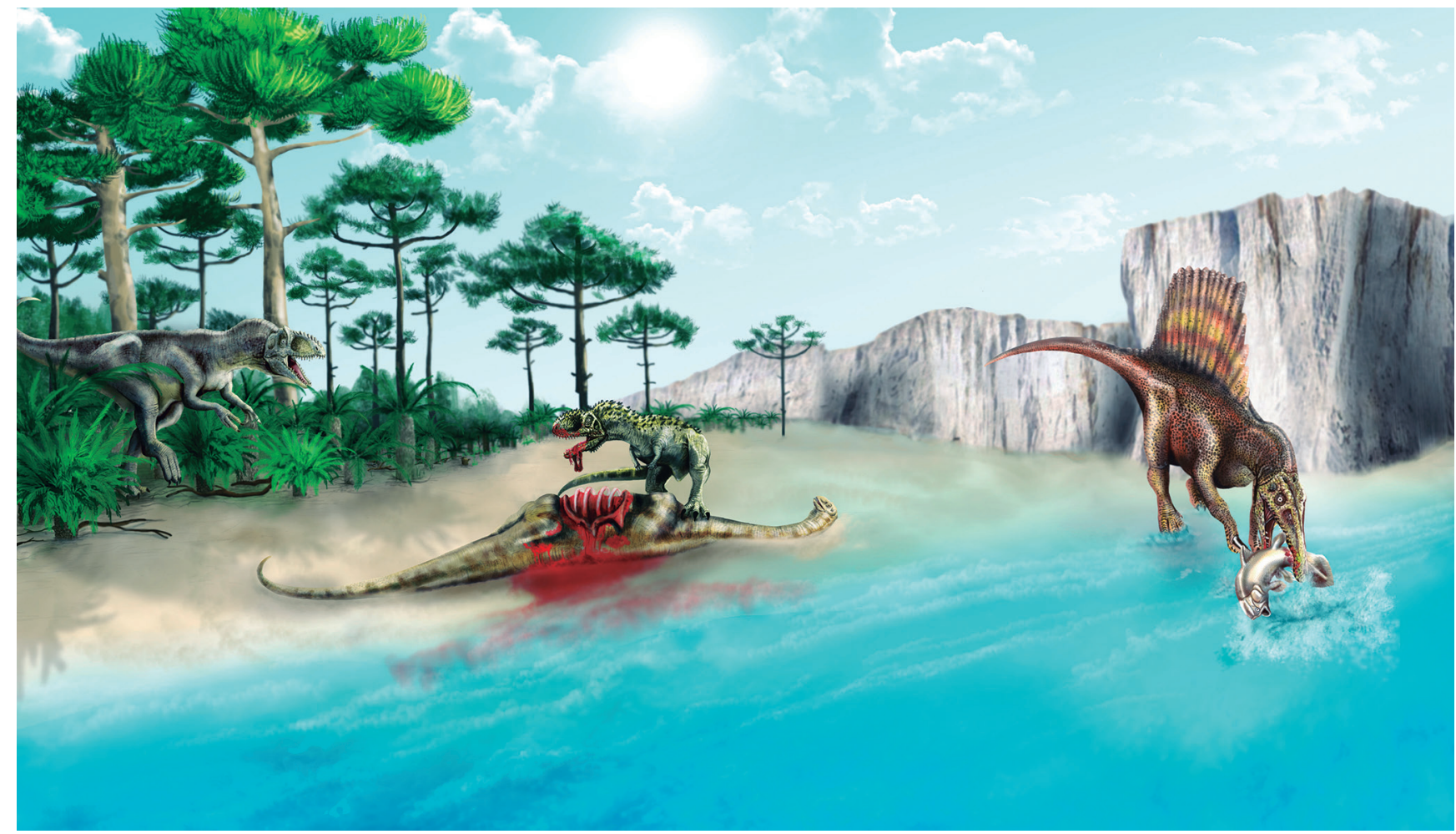

Figure 3. Paleoenvironmental reconstruction of large theropods from middle (retaceous North Africa showing carcharodontosaurid (left), abelisaurid (middle) and spinosaurid theropod (right) feeding. Drawing made by L. Vidal. 
but which can be the subject of future work. It may be that these groups ate slightly different prey, and in this sense the fish-eating habits of spinosaurids may have been particularly important to differentiate them from other large theropods. Or it could be that these large theropods hunted at different times (e.g., day vs. night), in slightly different habitats (e.g., forest vs. open plains), or in the style they hunted (e.g., pursuit vs. ambush). Or there could be other explanations. Whatever the reason, it is clear that these large theropods must have found a way to successfully live in the same faunas while eating generally similar foods, because all three groups were diverse and had great evolutionary success during the Early-middle Cretaceous.

\section{CONCLUDING REMARKS}

Carcharodontosaurids were some of the largest predatory dinosaurs to ever live. For many decades there were a mysterious group, represented by only a handful of fossils, but recent discoveries have revolutionized our understanding of their anatomy, systematics, phylogeny, biogeography, and evolution. The best record of carcharodontosaurids comes from northern Africa, where four species have been discovered. We reviewed this record and discussed how it shows that carcharodontosaurids were part of a general cosmopolitan dinosaur fauna that was globally distributed during the Earlymiddle Cretaceous, with particular affinities with South American taxa. We discussed how physical geography affected the evolution of carcharodontosaurids, particularly the slow fragmentation of Western Gondwana and its separation from Europe during the middle Cretaceous, and the waxing and waning of seaways that fragmented northern Africa into distinct provinces. We also noted how carcharodontosaurids are regularly found alongside fossils of two other types of giant theropods, spinosaurids and abelisaurids, and flagged several possible explanations for how these taxa could coexist while seemingly eating similar types of food. This review summarizes the state of knowledge on northern African carcharodontosaurids as it currently stands, and raises suggestions for future work that may help us better understand the evolutionary history of these fascinating dinosaurs.

\section{ACKNOWLEDGMENTS}

Brusatte is funded by a Marie Curie Career Integration Grant (EC 630652) and the University of Edinburgh. He thanks his former undergraduate mentor, Paul Sereno, for inviting him to work on what would become Carcharodontosaurus iguidensis, and sparking an interest in carcharodontosaurids. Thank to CR Scotese for paleomap authorization. This contribution was partially supported by the Conselho Nacional de Ciencia e Tecnologia Candeiro by Produtividade Pesquisa CNPq fellow.

\section{REFERENCES}

Amiot, R.; Buffetaut, E.; Lécuyer, C.; Wang, X.; Boudad, L.; Ding, Z. \& Zhou, Z. 2010. Oxygen isotope evidence for semi-aquatic habits among spinosaurid theropods. Geology, 38(2): 139-142.

Benson, R.B.J.; Barrett, P.; Rich, T.H. \& Vickers-Rich, P. 2010. A southern tyrant reptile. Science, 327: 1613-1613.

Benson, R.B.J.; Campione, N.E.; Carrano, M.T.; Mannion, P.D.; Sullivan, C.; Upchurch, P. \& Evans, D.C. 2014. Rates of dinosaur body mass evolution indicate 170 million years of sustained ecological innovation on the avian stem lineage. PLoS Biology, 12(5): e1001853.

Brusatte, S.L. \& Sereno, P.C. 2007. A new species of Carcharodontosaurus (Dinosauria: Theropoda) from the Cenomanian of Niger and a revision of the genus. Journal of Vertebrate Paleontology, 27(4): 902-916.

Brusatte, S.L.; Benson, RJ.B.; Carr, T.D.; Williamson, T.E. \& Sereno, P.C. 2007. The systematic utility of theropod enamel wrinkles. Journal of Vertebrate Paleontology, 27:1052-1056.

Brusatte, S.L. \& Sereno, P.C. 2008. Phylogeny of Allosauroidea (Dinosauria: Theropoda): comparative analysis and resolution. Journal of Systematic Paleontology, 6(2): 155-182.

Brusatte, S.L.; Benson, R.B.J.; Chure, D.J.; Xu, X.; Sullivan, C. \& Hone, D. 2009. The first definitive carcharodontosaurid (Dinosauria: Theropoda) from Asia and the delayed ascent of tyrannosaurids. Naturwissenschaften, 96: 1051-1058.

Brusatte, S.L.; Norell, M.A.; Carr, T.D.; Erickson, G.M.; Hutchinson, J.R.; Balanoff, A.M.; Bever, G.S.; Choiniere, J.N.; Makovicky, P.J. \& Xu, X. 2010a. Tyrannosaur paleobiology: new research on ancient exemplar organisms. Science, 329: 1481-1485.

Brusatte, S.L.; Chure, D.J.; Benson, R.B.J. \& Xu, X. 2010b. The osteology of Shaochilong maortuensis, a carcharodontosaurid (Dinosauria:Theropoda) from the Late Cretaceous of Asia. Zootaxa, 2334: 1-46.

Buffetaut, E. \& Ingavat, R. 1986. Unusual theropod dinosaur teeth from the Upper Jurassic of Phu Wiang, northeastern Thailand. Paléobiologie, 5: 217-20.

Buffetaut, E.; Martill, D.M. \& Escuillié, F. 2004. Pterosaurs as part of a spinosaur diet. Nature, 430: 33

Candeiro, C.R.A. 2015. Middle Cretaceous dinosaur assemblages from northern Brazil and northern Africa and their implications for northern Gondwanan composition. Journal South American Earth Sciences, 61: 147-153.

Candeiro, R.; Fanti, F.; Therrien, F. \& Lamanna, M. 2011. Continental fossil vertebrates from the mid-Cretaceous (Albian-Cenomanian) Alcântara Formation, Brazil, and their relationship with contemporaneous faunas from North Africa. Journal African Earth Sciences, 60: 79-92.

Carrano, M.T.; Benson, R.B.J. \& Sampson, S.D. 2012. The phylogeny of Tetanurae (Dinosauria: Theropoda). Journal of Systematic Paleontology, 10: 211-300.

Cau, A.; Dalla Vecchia, F.M. \& Fabbri, M. 2012. Evidence of a new carcharodontosaurid from the Upper Cretaceous of Morocco. Acta Palaeontologica Polonica, 57: 661-665.

Cavin, L.; Tong, H.; Boudal, L.; Meister, C.; Piuza, A.; Tabouelle, J.; Aarab, M.; Buffetaut, E., Dyke, G.; Huag, S. \& Loeuff, J.L. 2010 Vertebrate assemblages from the early Late Cretaceous of southeastern Morocco: an overview. Journal African Earth Sciences, 57: 391-412.

Charig, A.J. \& Milner, A.C. 1986. Baryonyx, a remarkable new theropod dinosaur. Nature, 324: 259-361.

Charig, A.J. \& Milner, A.C. 1997. Baryonyx walkeri, a fish-eating dinosaur from the Wealden of Surrey. Bulletin of Natural History Museum, 53: 11-70.

Chen, Z.; Li, Z.X.; Powell, C.M. \& Balme, B.E. 1993. Paleomagnetism of the Brewer Conglomerate in central Australia, and fact movement 
of Gondwanaland during the Late Devonian. Geophysical Journal International, 115: 564-574.

Coria, R.A. \& Currie, P.J. 2002. The braincase of Giganotosaurus carolinii (Dinosauria:Theropoda) from the Upper Cretaceous of Argentina. Journal of Vertebrate Paleontology, 22: 802-811.

Coria, R.A. \& Currie, P.J. 2006. A new carcharodontosaurid (Dinosauria, Theropoda) from the Upper Cretaceous of Argentina. Geodiversitas, 28: 71-118.

Coria, R.A. \& Salgado, L.A. 1995. New giant carnivorous dinosaur from the Cretaceous of Patagonia. Nature, 377: 224-226.

Cuff, A.R. \& Rayfield, E.J. 2013. Feeding mechanics in spinosaurid theropods and extant crocodilians. PLOS ONE, 8(5): e65295.

Currie, P.J. \& Zhao, X. 1993. A new carnosaur (Dinosauria, Theropoda) from the Jurassic of Xinjiang, People's Republic of China. Canadian Journal of Earth Sciences, 30(10): 2037-2081.

Dal Sasso, C.; Maganuco, S.; Buffetaut, E. \& Mendez, M.A. 2009. New information on the skull of the enigmatic theropod Spinosaurus, with remarks on its sizes and affinities. Journal of Vertebrate Paleontology, 25: 888-896.

Depéret, C. \& Savornin, J. 1927. Sur la découverte d'une faune de vertébrés albiens à Timimoun (Sahara occidental). Compentus Renduns Academie Science Paris, 181: 1108-1111.

Eddy, D.R. \& Clarke, J.A. 2011. New Information on the Cranial Anatomy of Acrocanthosaurus atokensis and its Implications for the Phylogeny of Allosauroidea (Dinosauria: Theropoda). PLoS ONE, 6: e17932.

Fanti, F. 2009. Cretaceous continental bridges, insularity, and vicariance in the southern hemisphere: which route did dinosaur take? In: Fanti, F. \& Spalletta, C. (Eds.). International conference on Vertebrate Palaeobiogeography and continental bridges across Tethys, Mesogea, and Mediterranean Sea. Abstract Book. Bologna, Museo Geologico Giovanni Capellini. 2 pp.

Fanti, F. 2012. (retaceous continental bridges, insularity, and vicariance in the southern hemisphere: which route did dinosaurs take? In: Talent, J. (Ed.). Earth and Life: Global biodiversity, extinction intervals and biogeographic perturbation trough time. London, Springer. p. 883-911.

Gatesy, J. \& Amato, G. 2008. The rapid accumulation of consistent molecular support for the intergeneric crocodilian relationships. Molecular Phylogenetics and Evolution, 48: 1232-1237.

Hendrickx, C. \& Mateus, 0. 2014. Abelisauridae (Dinosauria: Theropoda) from the Late Jurassic of Portugal and dentition-based phylogeny as a contribution for the identification of isolated theropod teeth. Zootaxa, 3759.

Holtz, T.R. 2004. Tyrannosauroidea. In: Weishampel, D.B.; Dodson, P. \& Osmólska, H. (Eds.). The Dinosauria. 2.ed. Berkeley,University of California Press. p. 111-136.

Ibrahim, N.; Sereno, P.C.; Dal Sasso, C.; Maganuco, S.; Fabbri, M.; Martill, D.M. \& lurino, D.A. 2014. Semiaquatic adaptations in a giant predatory dinosaur. Science, 345(6204): 1613-1616.

Kellner, A.W.A. 2004. On a pterosaur neck with a dinosaur tooth: scavenging or predation? Natura Nascota, 29: 37-39.

Kitchener, A. 1987. Function of Claws' claws. Nature, 325: 114

Krause, D.W.; Prasad, G.V.R.; von Koenigswald, W.; Sahni, A. \& Grine, F.E. 1997. Cosmopolitanism among Gondwanan Late Cretaceous mammals. Nature, 390: 504-507.

Lindoso, R.M.; Medeiros, M.A.A.; Carvalho, I.S. \& Marinho, T.S. 2012. Masiakasaurus-like theropod teeth from the Alcântara Formation, São Luís Basin (Cenomanian), northeastern Brazil. Cretaceous Research, 36: 119-124.

Lü, J.; Xu, L.; Pu, H.; Jia, S.; Azuma, Y.; Chang, H. \& Zhang, J. 2014. Paleogeographical significance of carcharodontosaurid teeth from the late Early Cretaceous of Ruyang, Henan Province of central China. Historical Biology, 25: 1-6.

Machado, E.B. \& Kellner, A.W.A. 2005. Notas sobre Spinosauridae (Theropoda, Dinosauria). Anais do Instituto de Geociências, 28: 158-173.

Marsh, 0.C. 1877. Notice of new dinosaurian reptiles from the Jurassic Formation. American Journal of Sciences, 84: 514-516.

McFeeters, B.; Ryan, M.J.; Hinic-Frlog, S. \& Schröder-Adams, C.J. 2013. A reevaluation of Sigilmassasaurus brevicollis (Dinosauria) from the Cretaceous of Morocco. Canadian Journal of Earth Sciences, 50(6): 636-649.

Medeiros, M.A.A. \& Schultz, C.L. 2002. A Fauna Dinossauriana da "Laje do Coringa", Cretáceo Médio do Nordeste do Brasil. Arquivos do Museu Nacional, 60: 155-162.

Metcalfe, I. 2006. Palaeozoic and Mesozoic tectonic evolution and palaeogeography of East Asian crustal fragments: the Korean Peninsula in context. Gondwana Research, 9: 24-46.

Milner, A.C. 2003. Fish-eating theropods: a short review of the systematics, biology and palaeobiology of spinosaurs. In: Huerta Hurtado, P. \& Torcida Férnandes-Baldor, F. (Eds). Journadas Internacionales sobre paleontologiá de Dinosaurios y su Entorno, 20, 2001. Actas. Burgos, Sala de los Enfantes. p. 129-138.

Naish, D.; Martill, D.M. \& Frey, E. 2004. Ecology, systematics and biogeographical relationships of dinosaurs, including a new theropod, from the Santana Formation (?Albian, Early Cretaceous) of Brazil. Historical Biology, 16: 57-70.

Nothdurft, W.; Smith, J.B.; Lamanna, M.C.; Lacovara, K.J.; Poole, J.C.; Smith, J.R. 2002. The Lost Dinosaurs of Egypt. New York, Random House. 242 p.

Novas, F.E.; Agnolín, F.L.; Ezcurra, M.D.; Porfiri, J. \& Canale, J.I. 2013. Evolution of the carnivorous dinosaurs during the Cretaceous: the evidence from Patagonia. Cretaceous Research, 45: 174-215.

Novas, F.E.; de Valais, S.; Vickers-Rich, P. \& Rich, T. 2005. A large Cretaceous theropod from Patagonia, Argentina, and the evolution of carcharodontosaurids. Naturwissenschaften, 92(5): 226-230.

Ortega, F.; Escao, F. \& Sand, J.L. 2010. A bizarre, humped Carcharodontosauria (Theropoda) from the Lower Cretaceous of Spain. Nature, 467: 203-206.

Rauhut, 0. 1999. A dinosaur fauna from the Late Cretaceous (Cenomanian) of northern Sudan. Paleontologica Africana, 35: 61-84.

Rauhut, 0.W.M. 2011. Theropod dinosaurs from the Late Jurassic of Tendaguru (Tanzania). Special Papers in Palaeontology, 86: 195-239.

Rayfield, E.J.; Milner, A.C.; Xuan, V.B. \& Young, P.G. 2007. Functional morphology of spinosaur 'crocodile-mimic' dinosaurs. Journal of Vertebrate Paleontology, 27: 892-901.

Sereno, P.C. 2005. The logical basis of phylogenetic taxonomy. Systematic Biology, 54 (42): 595-619.

Sereno, P.C. \& Brusatte, S.L. 2008. Basal abelisaurid and carcharodontosaurid theropods from the Lower Cretaceous Elrhaz Formation of Niger. Acta Palaeontogica Polonica, 53(1): 15-46.

Sereno, P.C.; Beck, A.L.; Dutheil, D.B.; Gado, B.; Larsson, H.C.; Lyon, G.H. \& Wilson, J.A. 1998. A long-snouted predatory dinosaur from Africa and the evolution of spinosaurids. Science, 282(5392): 1298-1302.

Sereno, P.C.; Dutheil, D.B.; larochene, M.; Larsson, H.C.E.; Lyon, G.H.; Magwene, P.M.; Sidor, C.A.; Varricchio, D.J. \& Wilson, J.A. 1996. Predatory dinosaurs from the Sahara and Late Cretaceous faunal differentiation. Science, 272: 986-99.

Sereno, P.C.; McAllister, S.; \& Brusatte, S.L. 2005. TaxonSearch: A relational database for suprageneric taxa and phylogenetic definitions. PhyloInformatics, 8(56): 1-25.

Stovall, J.W. \& Lanston, W. 1950. Acrocanthosaurus atokensis, a new genus and species of Lower Cretaceous Theropoda from Oklahoma. The American Midland Naturalist, 696-728. 
Stromer, E. 1915. Ergebnisse der Forschungsreisen Prof. E. Stromers in den Wüsten Kgyptens. II. Wirbeltier-Reste der Baharije-Stufe (unterstes (enoman). 3. Das Original des Theropoden Spinosaurus aegyptiacus nov. gen., nov. spec. Abhandlungen der Königlich Bayerischen Akademie der Wissenschaften, Mathematisch-physikalische Classe, 28: 1-32.

Stromer, E. 1931. Wirbeltiere-Reste der Baharijestufe (unterestes Canoman). Ein Skelett-Rest von Carcharodontosaurus nov. gen. Abhandlungen der Bayerischen Akademie der Wissenschaften, Mathematischnaturwissenschaftliche Abteilung, 9: 1-23.

Sues, H.D.; Frey, E.; Martill, D.M. \& Scott, D.M. 2002. Irritator challengeri, a spinosaurid (Dinosauria: Theropoda) from the Lower Cretaceous of Brazil. Journal of Vertebrate Paleontology, 22: 535-547.

Zanno, L.E. \& Makovicky, P.J. 2013. Neovenatorid theropods are apex predators in the Late Cretaceous of North America. Nature Communication, 4: 2827. 